\title{
El objeto directo anafórico de tercera persona en Oberá-Misiones: una mirada sociolingüística
}

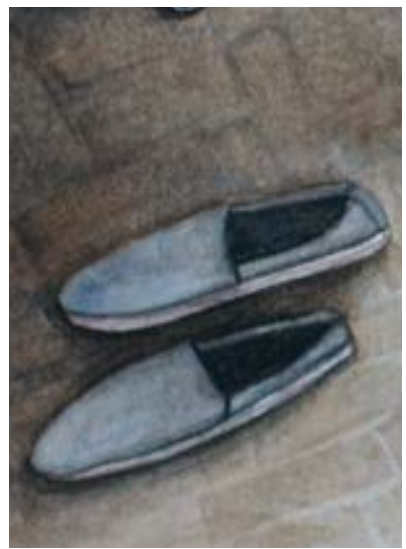

Patricia de Ramos

Universidade Federal do Rio de Janeiro, Brasil

pderamos@gmail.com

Leonardo Marcotulio

Universidade Federal do Rio de Janeiro, Brasil

leonardo.marcotulio@gmail.com

Trabajo recibido el 15 de enero de 2020 y aprobado el 26 de agosto de 2020 .

\section{Resumen}

Este artículo tiene como objetivo presentar la distribución de las estrategias de realización del objeto directo anafórico de tercera persona del español en términos de frecuencia de uso. La muestra de habla está compuesta por 19 entrevistas semidirigidas grabadas en 2015 en Oberá-Misiones (Argentina). El análisis cuantitativo demuestra que el marco de estrategias incluye los pronombres clíticos $l o(s) / l a(s)$, además del pronombre le(s) y del cero morfológico. La selección de las estrategias en variación es determinada, sobre todo, por la animacidad del referente y la escolaridad del hablante. La investigación nos permite concluir que el cuadro de estrategias observado indica un panorama de variación estable, ya que le(s) y cero se distribuyen obedeciendo a factores internos y, por lo tanto, no son sensibles al factor edad.

Palabras clave: clíticos, objeto directo, animacidad, escolaridad, sociolingüística

The direct anaphoric object of 3rd person in Oberá-Misiones: a sociolinguistic view

\footnotetext{
Abstract

This article aims to present the distribution of strategies for the realization of Spanish third-person anaphoric direct object in terms of frequency of use. The speech sample is composed of 19 semi-directed interviews recorded in
} 
2015 in Oberá-Misiones (Argentina). The quantitative analysis demonstrates that the strategy framework includes the $l o(s) / l a(s)$ pronouns, in addition to $l e(s)$ and morphological zero. The selection of the strategies in variation is mainly determined by the animacy of the referent and the schooling of the speaker. The investigation allows us to conclude that the observed strategy framework indicates a stable variation, once $l e(s)$ and zero are distributed following internal factors and, therefore, are not sensitive to the age of the informant.

Keywords: clitics, direct object, animacy, schooling, sociolinguistic

\section{O objeto direto anafórico de terceira pessoa em Oberá-Misiones: um olhar sociolinguístico}

\section{Resumo}

Este artigo tem como objetivo apresentar a distribuição das estratégias empregadas para a realização do objeto direto anafórico de terceira pessoa do espanhol em termos de frequência de uso. A amostra de fala está composta por 19 entrevistas semidirigidas gravadas em 2015 em OberáMisiones (Argentina). A análise quantitativa demonstra que o quadro de estratégias inclui os pronomes $l o(s) / l a(s)$, além do pronome le(s) e do zero morfológico. A seleção das estratégias em variação encontra-se determinada, principalmente, pela animacidade do referente e a escolaridade do falante. A nossa investigação permite concluir que o quadro de estratégias observado aponta para um cenário de variação estável, uma vez que le(s) e zero distribuem-se obedecendo a fatores internos e, portanto, não são sensíveis ao fator idade do informante.

Palavras-chave: clíticos, objeto direto, animacidade, escolaridade, sociolinguística

\section{Introducción}

En este artículo, estudiamos la frecuencia de uso de las estrategias elegidas por los hablantes de Oberá para la realización del objeto directo (OD) anafórico de tercera persona. La fundamentación teórica-metodológica es la de la sociolingüística variacionista cuantitativa de Labov (Weinreich, Labov y Herzog 1968; Labov 1972, 1994) aplicada a una muestra de habla. Oberá se ubica en la provincia de Misiones, al noreste de Argentina, y tiene una población de 107.501 habitantes. Para llevar a cabo el análisis, hemos constituido una muestra de habla de la variedad del español que se habla en Oberá. La misma fue recogida entre hablantes de la región, hombres y mujeres de diferentes generaciones y con distinto nivel de escolaridad.

El objetivo de este artículo es demostrar la distribución de las estrategias de realización del objeto directo anafórico de $3^{a}$ persona en el español en Oberá: los clíticos lo(s)/la(s) (1a-b), el clítico le(s) (2), el cero morfológico (3), el sintagma nominal (4) y el pronombre demostrativo (5), como se observa a continuación. 
(1) a. l17: Y según lo que yo me enteré de que el chavón era gendarme ¿no? y era e: a la misma era ladrón de coche se ponía a robar autos entonces [un policia] justo lo pesca y: él agarro y lo mata al policía (Hombre, generación 2, nivel secundario)

b. E: Bien a: ¿Usted tiene [mascota $]_{i}$ ?

19: No

E: No

l19: Ahora no hace poco la tuve (Mujer, generación 3, nivel superior)

(2) E: Y ¿conocias a [esas personas] $]_{i}$ ?

l17: Yo le conocía sî porque se murió un bebé y una vieja (Hombre, generación 2, nivel secundario)

(3) E: A: vamos a pasar esto ¿qué opinás de este accidente conocés [este accidente] $]_{i}$ ? ¿por qué pasó?

l11: $\emptyset_{i}$ Conozco y puedo decirte que se hubiera evitado (Mujer, generación 3, nivel superior)

(4) E: Y después de ese accidente hicieron un homenaje ¿qué me contás sobre ese? Hay [un monumento] en la plaza pero ((ruido)

I4: Mirá yo vî el monumento, no participé del acto escuché e: (Mujer, generación 2nivel superior)

(5) E: Bien en relación / T usted conoce a a [este hombre $]_{i}$ ?

16: Este hombre ... yo parece que vi en la tele ese $e_{i}$ (Mujer, generación 3, nivel inicial)

Prestaremos especial atención al uso de le(s), una vez que la literatura sobre el sistema pronominal átono afirma que en Misiones y en otras regiones al noreste de Argentina, y en Paraguay, le retoma antecedentes sin distinción de género, de número y del grado de animacidad. Nuestra hipótesis es que además de le(s), los hablantes en Oberá seleccionan otras formas para la realización del objeto directo anafórico de $3^{a}$ persona, como los clíticos lo(s)/ la(s), el cero morfológico, el sintagma nominal y el pronombre demostrativo.

Además, discutiremos la relevancia de los factores animacidad del referente, escolaridad y edad del hablante en la selección de las estrategias observadas. Nuestro estudio contribuye con la literatura sobre el sistema pronominal átono del español, una vez que realiza un análisis cuantitativo de una variedad que ha sido poco contemplada hasta el momento.

Este artículo - que sintetiza los principales resultados de la tesis de máster de de Ramos (2017), en el que optamos por una visión amplia del tema y no por el análisis profundizado de uno u otro factor (extra)lingüístico- se organiza de la siguiente manera: §1 presenta el estado de la cuestión sobre el sistema pronominal átono de tercera persona; \$2 introduce las preguntas que guían nuestra investigación y la hipótesis de nuestro trabajo; §3 describe la constitución del corpus; §4 se centra en las variables sociolingüísticas controladas; §5 presenta el análisis de los datos, empezando por el punto de partida, seguido del análisis del factor género del referente. En seguida, analizamos el factor animacidad del referente, seguido de los factores externos género y escolaridad del informante y por último el cruce 
entre escolaridad y género del informante. $\$ 6$ plantea la importancia del factor edad en nuestro estudio. Finalmente, $\$ 7$ presenta las conclusiones.

\section{Estado de la cuestión}

Antes de presentar algunos de los principales trabajos sobre el sistema pronominal átono de tercera persona, explicamos qué entendemos por objeto directo anafórico. Para tanto, primero nos centramos en el objeto directo (de ahora en más OD) y después explicaremos su particularidad anafórica.

Es un hecho conocido que uno de los problemas más difíciles de solucionar al estudiar el sistema pronominal átono es la distinción entre los llamados objetos directo e indirecto. Para el análisis que proponemos en este estudio nos parece muy indicada la explicación de Laca $(2006,423)$, quien entiende que el OD es un argumento estructuralmente adyacente a una forma verbal activa que lo rige. Según la autora, este argumento puede caracterizarse por una serie de propiedades formales, entre las cuales se destaca su asociación con el caso acusativo. Aun según la misma autora, en español, desde sus orígenes, la asociación con el caso acusativo se detecta mediante la posibilidad de sustituirlo o duplicarlo por un clítico de la serie acusativa $l o(s) / l a(s)$.

Es preciso señalar lo que menciona una de las referencias más importantes de la lengua española sobre el tema. Se trata de la Nueva Gramática de la Lengua Española (2009). Según esta gramática, se entiende por objeto directo (OD) "la función sintáctica dependiente del verbo que puede ser desempeñada, dentro del grupo verbal, por varios segmentos sintácticos -nombres, pronombre y los grupos que forman-" (RAE y ASALE 2009, 2591). El OD corresponde al caso acusativo en latín, que en español se manifiesta morfológicamente en el sistema pronominal. Así, el grupo nominal la ventana es el OD del verbo transitivo abrir en la oración Abrí la ventana y la oración asistir al acto de clausura es el OD del verbo prometer en Prometió asistir al acto de clausura (Nueva Gramática de la Lengua Española 2009, 2591).

Por su parte, por anáfora se entiende la relación que establece una palabra, generalmente un pronombre, con otra(s) mencionada(s) previamente en el discurso y que permite determinar cuál es su referente (Lázaro Carreter 1968). El pronombre anafórico alude normalmente, desde la oración en la que se halla enclavado, a los elementos de otra oración anterior (subordinada, subordinante, coordinada, etc.). Por ejemplo: volvió con un porrón y lo dejó encima de la mesa (Fernández Ramírez 1951, 58). En este caso, el pronombre lo alude a porrón que está en la oración coordinada anterior. Fernández Ramírez indica que, en determinadas circunstancias, el elemento anafórico puede referirse a elementos de su propia oración. Sin embargo, en este trabajo, seguimos lo señalado por Quilis et al (1985) y Gómez Seibane (2012). Por lo tanto, consideramos que, si el OD aparece en la misma oración que el elemento referido, estamos delante de un caso de duplicación del OD. Por ejemplo: La casa la compró mi padre (Quilis et 
al 1985, 99); A Lucía la vieron salir (Gómez Seibane 2012, 52); A Juana la eligieron presidenta (Gómez Seibane 2012, 52). Con todo, el OD es anafórico cuando establece una relación con el constituyente mencionado previamente en el discurso, o sea, su referente. Veamos a continuación algunos de los principales estudios sobre el sistema pronominal átono de tercera persona, que incluye el estudio del OD.

La variación del sistema pronominal átono ha sido estudiada desde una multitud de enfoques, tanto en trabajos de corte sincrónico como diacrónicos. En este artículo, es importante sintetizar aquellos trabajos que realizan un estado de la cuestión detallada del fenómeno y aquellos que estudian

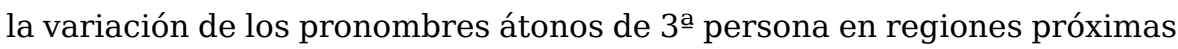
a Oberá.

Siendo así, por un lado, destacamos tres trabajos que realizan un estado de la cuestión cautelosa sobre el sistema pronominal átono de tercera persona y que contribuyen de modo significativo en nuestro estudio. En primer lugar, Klein-Andreu $(1981,284)$ señala la existencia de dos sistemas: el casual (o etimológico) y el referencial. El primero se basa en la distinción de caso - lo(s)/la(s) acusativo y le(s) dativo-; el segundo no responde a las distinciones de caso, sino que parece reflejar otras características semánticas del objeto referido como la animacidad, la definitud o la determinación. En segundo lugar, nos referimos al Klein-Andreu (1992, 170), quien indica que el de facto estándar peninsular distingue caso excepto en referencias animadas masculinas, situación en la que se usa el clítico le(s), independientemente de su función en el enunciado. La misma autora (Klein-Andreu 1992, 172) comenta que algunos gramáticos plantean la existencia de un sistema "de compromiso" que estaría entre el casual y el referencial y que caracteriza la lengua culta peninsular. Finalmente, del exhaustivo trabajo de Fernández-Ordóñez (1993) subrayamos la necesidad indicada por la autora de distinguir, en el estudio del sistema pronominal átono, el uso de los pronombres en las regiones estudiadas del llamado uso estándar. En otras palabras, la necesidad de conocer el sistema en una determinada región y diferenciarlo, o no, del "estándar".

Por otro lado, destacamos trabajos que analizan las variedades del español del noreste de Argentina y de Paraguay. Amable (1975) indica que el clítico $l e$ en singular alude a referentes tanto en singular como en plural en el habla de Misiones. De modo similar, de Granda (1982, 262-263) afirma que el uso de le para el OD presenta dos rasgos totalmente diferentes a los encontrados en el español en la Península y, a lo que parece, de otras variedades del español en América: i) la absoluta generalidad, abarcando antecedentes humanos, animados e inanimados, sean masculinos o femeninos, singular o plural y ii) su invariabilidad formal ${ }^{1}$, ya que le funciona como única forma de OD para la totalidad de los casos posibles, sin considerar el género, el número o la semántica del objeto al que se refiere. Posteriormente, Palacios $(2000,2005)$, a partir de estudios de caso, reitera lo ya mencionado por de Granda (1982) y afirma que el empleo de este 
clítico ha sido la característica más relevante del español paraguayo, se encuentra en los distintos estratos sociales del país y los factores edad y género del informante no parecen determinar cambios relevantes en el uso. Martínez (2006, 2010) y Gómez Seibane (2012) comparten esa opinión y comprueban una vez más que el factor animacidad del referente no es determinante en la selección de le.

Aún sobre las mismas regiones, de Granda (1982) y Palacios (1998) indican que existe en Paraguay la posibilidad del objeto nulo, o cero morfológico, que se emplea de forma no sistematizada. Desde una perspectiva de las lenguas en contacto, Palacios (1998) analiza la elisión de pronombres de objeto con referentes inanimados y concluye que esa construcción aparece de forma generalizada en el español paraguayo y que no es un fenómeno aislado, una vez que puede aparecer en otras lenguas románicas.

Los estudios mencionados anteriormente plantean el uso variable de los pronombres átonos de $3^{\underline{a}}$ persona. Con todo, en nuestra opinión, notamos que se ha prestado poca atención a la región de Oberá-Misiones. Siendo así, nuestro estudio sociolingüístico se justifica por realizar un análisis cuantitativo en una variedad del español que ha sido poco contemplada entre los expertos sobre OD. A continuación, en §2 presentamos el objetivo del estudio.

\section{El objetivo del estudio}

Esta investigación se inscribe en el marco teórico de la sociolingüística variacionista cuantitativa de Labov (Weinreich, Labov, Herzog 1968; Labov $1972,1994)$ y busca responder las siguientes preguntas: ¿Qué factores externos rigen la distribución de las estrategias para la realización del objeto directo anafórico de $3^{\mathrm{a}}$ persona en Oberá? ¿Qué factores internos son determinantes en la variación? ¿El pronombre le(s) es la forma más frecuente de realización del OD anafórico de $3^{\underline{a}}$ persona? ¿El panorama es de variación estable o de cambio en curso?

Nuestra hipótesis es que además de $l e(s)$, los hablantes en Oberá seleccionan otras formas para la realización del objeto directo anafórico de $3^{\text {a }}$ persona, como los clíticos lo(s)/la(s), el cero morfológico, el sintagma nominal y el pronombre demostrativo.

La predicción que se desprende de nuestra hipótesis es que la distribución de las estrategias le(s) y cero se encuentra determinada, más que nada, por factores lingüísticos, con mayor énfasis en la animacidad del referente. Del mismo modo, los pronombres clíticos lo(s)/la(s)no compiten con las demás estrategias porque son las formas de mayor prestigio social y se encuentran determinadas, sobre todo, por los factores externos género y escolaridad del informante. Y finalmente, le(s) y cero no son sensibles al factor generación, lo que indicaría un panorama de variación estable y no de cambio en progreso. 


\section{Constitución del corpus}

Para investigar la distribución de las estrategias de realización del objeto directo anafórico de $3^{\underline{a}}$ persona hemos constituido una muestra del habla en Oberá. La misma está compuesta por 19 entrevistas semidirigidas que fueron grabadas en 2015. Para su elaboración, controlamos factores sociolingüísticos como la edad, el género y el grado de escolaridad del hablante. En la tabla 1 a continuación presentamos la distribución de los informantes de acuerdo con los factores controlados.

\begin{tabular}{|c|c|c|c|c|c|c|}
\hline \multirow{2}{*}{$\begin{array}{l}\text { Escolaridad/ } \\
\text { edad/género }\end{array}$} & \multicolumn{2}{|c|}{ Nivel 1 de escolaridad } & \multicolumn{2}{|c|}{ Nivel 2 de escolaridad } & \multicolumn{2}{|c|}{ Nivel 3 de escolaridad } \\
\hline & mujer & hombre & mujer & hombre & mujer & hombre \\
\hline $\begin{array}{l}\text { Generación } \\
\text { A }\end{array}$ & & & (19 años) & (19 años) & $\begin{array}{l}\text { (19 años) } \\
\text { (19 años) } \\
\text { (18 años) }\end{array}$ & \\
\hline $\begin{array}{l}\text { Generación } \\
\text { B }\end{array}$ & & (22 años) & $\begin{array}{l}\text { (31 años) } \\
\text { (30 años) }\end{array}$ & (21 años) & $\begin{array}{l}\text { (23 años) } \\
\text { (25 años) }\end{array}$ & \\
\hline $\begin{array}{l}\text { Generación } \\
\text { C }\end{array}$ & $\begin{array}{l}\text { (52 años) } \\
\text { (56 años) }\end{array}$ & (62 años) & & & $\begin{array}{l}\text { (50 años) } \\
\text { (58 años) } \\
\text { (56 años) }\end{array}$ & $\begin{array}{l}\text { (49 años) } \\
\text { (54 años) }\end{array}$ \\
\hline
\end{tabular}

Tabla 1: Distribución de los informantes de acuerdo con los factores controlados.

Observamos que hay casillas vacías y otras con un número mayor de informantes. Ello se debe al hecho de que encontramos algunas dificultades a la hora de buscar informantes. Además, es importante señalar que la diferencia en el número de datos entre hombres y mujeres se debe a la diferencia en el número de informantes. De los diecinueve informantes, solo fue posible entrevistar a seis hombres.

Las entrevistas fueron grabadas en diciembre de 2015 en el departamento de Oberá, en Misiones (Argentina). Las mismas tienen una duración que varía entre 20 y 45 minutos. La división de los informantes en tres generaciones se debe a un criterio aplicado durante la realización de las entrevistas y tiene que ver con el perfil de los informantes. La Generación A tiene menos de 20 años, la Generación B tiene entre 20 y 50 años y la Generación C tiene más de 50 años. Los niveles de escolaridad se distribuyen entre primaria (in)completa, secundaria (in)completa y terciario (in)completo.

La metodología empleada es la prevista por la sociolingüística cuantitativa de Labov, o sea, una entrevista semidirigida y una narrativa espontánea. Formulamos un módulo de preguntas para la colecta de datos. El mismo cubría una serie de temas para fines conversacionales. Entre ellos, preguntas relacionadas al cotidiano, la profesión, los medios de transporte, la política, la religión, las utopías, la infancia y el lenguaje. Preparamos una presentación en el programa Power-Point con imágenes vinculadas a las preguntas, que tenía doble objetivo: i) servir de base para que los informantes desarrollaran sus argumentos y ii) que funcionara como distractor. 
Como esperábamos una narrativa, buscamos algún momento de mayor distracción del informante y planteamos una pregunta que tenía que ver con alguna experiencia o relato de vida. Para no condicionar a los informantes, no mencionamos el objetivo real de las grabaciones, pero sí se dio a conocer el hecho de que serían grabados.

Una vez grabadas las entrevistas, el próximo paso fue la transcripción de las mismas. Para ello, utilizamos las convenciones empleadas para la transcripción de los datos del Corpus Concordância de la Universidade Federal do Rio de Janeiro (UFRJ) ${ }^{2}$. El paso siguiente fue la búsqueda y codificación de los datos. Para el análisis cuantitativo utilizamos el programa computacional GoldVarbX (Sankoff, Tagliamonte, Smith 2005) que mide los valores absolutos de la frecuencia de uso y el porcentaje de cada una de las variantes encontradas.

\section{Variable dependiente y variables independientes}

A partir de la revisión de la bibliografía sobre el tema, seleccionamos las posibles variantes, o formas de realización del objeto directo anafórico de 3 a persona en español. En ese sentido, seleccionamos cinco formas posibles. Son ellas: los clíticos acusativos lo(s)/la(s) (a); el clítico dativo le(s) (b); la ausencia de un elemento morfológico, que denominamos cero morfológico (c); el sintagma nominal (SN) (d), idéntico o parecido al referente; y, finalmente, el pronombre demostrativo (Dem) (e). Ese conjunto de estrategias, o variantes, es, en nuestro estudio sociolingüístico, la variable dependiente.

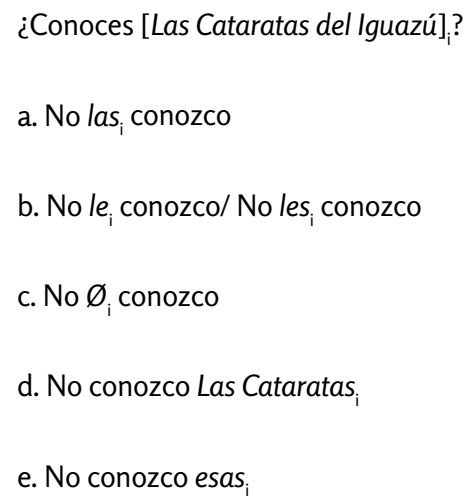

Para conocer la distribución de las posibles formas para la realización del OD anafórico en términos de frecuencia de uso, es necesario relacionarlas con factores que pueden condicionar la selección de una u otra forma. En ese sentido, dentro de la sociolingüística laboviana se denomina variable independiente cada uno de los factores lingüísticos y no lingüísticos que pueden influir en el uso de una o de otra variante lingüística. Así, por un lado, podemos citar la animacidad, el número y el género del referente como 
factores lingüísticos. Por otro lado, el género, la escolaridad y la edad del informante como factores extralingüísticos.

\section{El análisis}

\subsection{Punto de partida}

En la tabla 2 presentamos los resultados generales de nuestra investigación.

\begin{tabular}{cc}
\hline cero & $247 / 816-30,3 \%$ \\
\hline $\mathrm{lo}(\mathrm{s}) / \mathrm{la}(\mathrm{s})$ & $214 / 816-26,2 \%$ \\
\hline $\mathrm{le}(\mathrm{s})$ & $190 / 816-23,3 \%$ \\
\hline $\mathrm{SN}$ & $127 / 816-15,6 \%$ \\
\hline demostrativo & $38 / 816-4,7 \%$ \\
\hline
\end{tabular}

Tabla 2: Resultados generales

Con esta tabla, en la que presentamos los valores absolutos de la frecuencia de uso de las estrategias de retomada del OD anafórico de $3^{a}$ persona, podemos conocer datos importantes para nuestro estudio. Observamos que la estrategia más productiva es el cero morfológico, ejemplo (6), con 247 datos de 816 , que corresponde al $30 \%$ del total. La segunda estrategia más frecuente son los clíticos lo(s)/la(s), ejemplo (7), (214/816), que equivale al $26,2 \%$ del total. El clítico le(s) es tan solo la tercera estrategia más frecuente, como vemos en el ejemplo (8), encontramos 190 apariciones, que corresponde al 23,3\% del total. Las dos formas menos frecuentes de realización del OD anafórico fueron el $S N(127 / 816$ - 15,6 \%) y el pronombre demostrativo (38/816 - 4,7 \%), como vemos en los ejemplos (9) y (10) respectivamente.

(6) $\mathrm{E}^{3}$ : Entonces ¿Los padres no controlan según vos no controlan mucho a [los chicos] ${ }_{i}^{4}$ ? l12: Claro no tanto algunos sí pero generalmente la sociedad está así que no que no están controlando $\varnothing_{\mathrm{i}}^{5}$ (Mujer, generación 1, nivel terciario)

(7) $l_{19}$ [...] esto lleva a que [los chicos $]_{i}$ estén desprotegidos porque en última instancia ellos se revelan ellos quieren ser independientes ellos no quieren control pero cunado los padres de una familia o los docentes dejamos de estar cerca de ellos los estamos $^{\circ}$ dejando vulnerables (Mujer, generación 3, nivel terciario)

(8) Is: [...] por ejemplo un [una víbora $]_{i}$ la gente $l_{i}$ mata a golpe terrible porque para qué vino acá ese animal (Mujer, generación 3, nivel inicial)

(9) 16: sí hice e: hice varias varias materias a ver e: el primer año tuvimos unas materias que es exposición discursiva que se lleva todo lo que es mapa y todas esas cosas e: después tenemos gramáticas que es el tema de [las oraciones $]_{i}$ analizar las oraciones ${ }_{i}$ (Mujer, generación 1, nivel superior)

3 En los ejemplos, <E> corresponde a la entrevistadora; <I + un número > al informante.

4 Entre corchetes, en cursiva e indexado ponemos el referente.

5 En cursiva e indexado presentamos las estrategias de realización del OD anafórico de $3^{\underline{a}}$ persona. 
(10) E: Bien en relación / T usted conoce a a [este hombre $]_{i}$ ?

16: Este hombre ... yo parece que vi en la tele ese ${ }_{i}$ (Mujer, generación 3, nivel inicial)

Esperábamos encontrar en la muestra de habla de Oberá un número mucho mayor de realizaciones de le(s) que de los pronombres lo/la y sus plurales. Sin embargo, en nuestro corpus le(s) es tan solo la tercera estrategia. Ese resultado despierta nuestro interés y, por esa razón, buscamos entender mejor qué factores estarían por detrás de los resultados generales.

\subsection{El género del referente}

En esta sección nos interesa dar a conocer la distribución de las variantes en función del género del referente, con énfasis en el uso de los pronombres clíticos $l o(s) / l a(s)$ y $l e(s)$. En la tabla 3 vemos los resultados obtenidos:

\begin{tabular}{lll}
\cline { 2 - 3 } & masculino & femenino \\
\hline $\mathrm{le}(\mathrm{s})$ & $137 / 447-30,6 \%$ & $53 / 284-18,7 \%$ \\
\hline $\mathrm{lo}(\mathrm{s})^{6}$ & $125 / 447-28 \%$ & $11 / 284-3,9 \%$ \\
\hline $\mathrm{la}(\mathrm{s})$ & - & $57 / 284-20,1 \%$ \\
\hline cero & $115 / 447-25,7 \%$ & $93 / 284-32,7 \%$ \\
\hline $\mathrm{SN}$ & $61 / 447-13,6 \%$ & $63 / 284-22,2 \%$ \\
\hline dem. & $9 / 447-2 \%$ & $7 / 284-2,5 \%$ \\
\hline Tabla 3: Género del referente & &
\end{tabular}

Tabla 3: Género del referente

De modo global, se emplea mayoritariamente el pronombre clítico le(s) para referentes masculinos $(30,6 \%)$ y cero para femeninos $(32,7 \%)$. Considerando los referentes masculinos, la segunda forma con mayor frecuencia de uso es el pronombre $l o(s)$ (28\%), seguida del cero $(25,7$ $\%)$. Las dos menos frecuentes son el $S N$ (13.6 \%) y el demostrativo (2\%). Por otro lado, considerando los antecedentes femeninos, la segunda estrategia más frecuente es el pronombre $l a(s)(20,1 \%)$. El $S N$ es la tercera estrategia más empleada $(22,2 \%)$, seguido del pronombre clítico le(s) (18,7\%); el demostrativo solo llega a 2,5\% de las apariciones. Es interesante resaltar que tanto $l e(s)$ como cero aluden a referentes masculinos y femeninos, de forma bastante equilibrada, aunque no son las únicas estrategias posibles.

Los resultados de la tabla 3 coinciden parcialmente con lo señalado en la literatura lingüística para el noreste de Argentina (Amable 1975; de Granda 1982; Palacios 1998, 2005; Martínez 2006, 2010; Gómez Seibane 2012), que describe el empleo extendido de la forma le para todos los sustantivos, con independencia de los rasgos semánticos concordantes, como el género y el número. Con todo, podemos ver que el marco de estrategias de realización del OD anafórico de $3^{a}$ persona en Oberá cuenta también con los pronombres clíticos $l o(s) / l a(s)$, con frecuencias de uso relativamente altas. Con todo, nuestros datos se alejan de lo descrito para otras regiones del español y del llamado estándar. Por un lado, el pronombre le no se relaciona 
en absoluto con los objetos directos masculinos, como podemos ver en los ejemplos (11) y (12):

(11) Le [masculino]:

a) E: La policía arrestó a $[L]_{i}$ por acá alrededor eso me contaron

14: Yo la verdad es que no sé yo le vi en (Mujer, generación 2, nivel terciario)

b) 16: Claro y por eso yo digo la lala gente no respeta a la policía y la policía no respeta tampoco y la justicia no ayuda a los policías ponele que la policía rescata [los bandidos] llevan ahí llegan allá en el juez el juez le suelta viste (Mujer, generación 3, nivel inicial)

(12) Le [femenino]:

a) I7: [...] cuando yo me acompañé con [tu mamá] $]_{i}$ la noche que yo me acompañé con ella dice que era una hembra era una pandera porque que no le quería a ella (Hombre, generación 3, nivel inicial)

b) 10: Bueno uno de [una amiga $]_{\text {q }}$ que yo nunca me voy a olvidar e: fue una tragedia que le $e_{i}$ perdí a ella (Mujer, generación 1, nivel inicial)

Por otro lado, observamos que las estrategias $l o(s) / l a(s)$ tienen una frecuencia de uso relativamente alta, diferentemente a lo descrito en la literatura especializada. Llama mucho la atención el uso de esos pronombres, ya que encontramos 10 datos de lo para el OD femenino, como vemos en los ejemplos que mostramos a continuación.

\section{Lo [femenino]:}

(13) l13: Y bueno la verdad que no entendía nada no di computación en el colegio pero cuando tuve [mi computadora $]_{i}$ mi propia computadora bueno empezamos a bajar programas empezamos a trabajar con eso al principio como que bueno era sorprendente tener una computadora que queríamos e: nos bajábamos jueguito porque incluso no nos prohibían o sea bajarnos juegos podíamos hacer eso y yo $l_{i}$ utilicé muy poco para el colegio porque después se e: tuvo un problema la computadora y $l_{i}$ llevé al servicio técnico (Mujer, generación 1, nivel superior)

(14) l11: el play si varios hechos por ejemplo [mi fiesta de quince $]_{i}$ que $l_{i}$ esperaba con ansiedad tremenda (Mujer, generación 2, nivel superior)

(15) l18: e: la dificultad que te nombraría es es que está poco e: poco e: o sea no hay materiales no hay insumos no hay este buenos apar/ buenos equipamientos en las salitas pero igualmente se pueden hacer [muchas cosas $]_{i}$ que de hecho $l_{i}$, hago e: en la prevención que ya te digo se puede y se debe hacer (Mujer, generación 3, nivel superior)

En el ejemplo (13) el grupo nominal mi computadora es referido en la tercera y en la quinta mención por el pronombre lo. La primera, la segunda y la quinta menciones se llevan a cabo por un sintagma nominal parecido al referente - mi propia computadora, una computadora, la computadoralo que, en principio, refuerza la idea de que el hablante es consciente de que el objeto aludido es femenino. Es relevante también el hecho de que la informante es una mujer con menos de 20 años y que cursa el nivel terciario. 
En el ejemplo (14) el sintagma nominal mi fiesta de quince, femenino de cosa, es referido por el pronombre lo en el habla de una mujer que tiene más de 20 años, que cursa el nivel superior.

En (15) el sintagma muchas cosas, femenino de cosa, es referido por el pronombre lo en singular en el habla de una mujer que tiene más de 50 años y que tiene el nivel superior completo.

Como demuestran los ejemplos (13) a (15), el pronombre lo en Oberá puede aludir a referentes femeninos. Estos ejemplos aparecen en el habla de informantes de género femenino y que, en nuestra muestra, poseen el mayor índice de escolaridad.

Varias son las perspectivas de análisis y las explicaciones del uso variable de los clíticos en español. Nuestros resultados generales apuntan también un uso variable de las formas de realización del OD anafórico de $3^{a}$ persona, entre las que se encuentran los pronombres $l o(s) / l a(s)$ y $l e(s)$. En ese sentido, al igual que otros estudiosos, nos preguntamos ¿qué factores influyen en la selección de las formas analizadas? Para responder esa pregunta, analizamos la distribución de las variantes en función de factores lingüísticos y extralingüísticos.

\subsection{El factor intralingüístico animacidad del referente}

Observamos a continuación cómo influye el factor animacidad del referente en la variación de las estrategias analizadas. Como mencionamos en §2, la predicción que se desprende de nuestra hipótesis es que la distribución de las estrategias le(s) y cero se encuentra determinada, mayormente, por factores lingüísticos, con mayor énfasis en la animacidad del referente. La tabla 4 nos permite ver los resultados encontrados.

\begin{tabular}{llll}
\cline { 2 - 4 } & humano & animado & inanimado \\
\hline le(s) & $159 / 331-48 \%$ & $28 / 88-31,8 \%$ & $3 / 312-1 \%$ \\
\hline lo(s)/la(s) & $92 / 331-27,8 \%$ & $30 / 88-34,1 \%$ & $71 / 312-22,8 \%$ \\
\hline cero & $51 / 331-15,4 \%$ & $18 / 88-20,5 \%$ & $139 / 312-44,6 \%$ \\
\hline SN & $28 / 331-8,5 \%$ & $8 / 88-9,1 \%$ & $88 / 312-28,2 \%$ \\
\hline dem. & $1 / 331-0,3 \%$ & $4 / 88-4,5 \%$ & $11 / 312-3,5 \%$ \\
\hline
\end{tabular}

Tabla 4: Animacidad del referente

Como vemos en la tabla 4, la predicción se comprueba. La estrategia más frecuente para el OD humano es $l e(s)-48 \%(159 / 331)$ - y para el OD inanimado es cero $-44,6 \%$ (139/312) - . Mostramos esos resultados en los ejemplos (16) y (17) respectivamente.

(16) l17: $Y$ tengo algunas amigas pero las amigas [las chicas] $]_{i}$ por más los viejos le tienen más cortas ponele no lei dejan salir (Hombre, generación 2, nivel secundario) 
(17) E: [Los mitos y las leyendas]

19: Creo que que desde la lingüística se $\emptyset_{i}$ trata o sea los mitos y leyendas forman parte de contenidos que se enseñan y en las escuelas secundarias (Mujer, generación 3, nivel superior)

No podemos dejar de mencionar que, con referentes animados, es decir, no personales, notamos una distribución equilibrada entre los pronombres $l e(s)$ y $l o(s) / l a(s)$, como vemos en (18) y (19) respectivamente.

(18) lio una vez [un lorito] que me regaló mi papá y estaba en la orilla de la silla y un perro ladró al lado de él y como yo le corté la alita por malvada también/ no es muy querer también porque si uno $l e_{i}$ quiere no le va a cortar la alita ¿no? Le corté la alita y le puse en la orilla me fui a jugar con mi amiga y le dejé con mi mamá el lorito (Mujer, generación 1, secundario)

(19) que no está cuidada como debería estar cuidada no hay /acá cerca de tres cuadras tenés el jardín de los pájaros y no no no no le prestan el debido cuidado a [los animales] que debería tener por ejemplos se escapan no los devuelven (Mujer, generación 3 , nivel superior)

En síntesis, los resultados de la tabla 4 indican que el factor animacidad del referente es un factor que condiciona la distribución de las estrategias analizadas. Cuando el referente es humano se emplea mayoritariamente el pronombre $l e(s)$, mientras que para referentes inanimados la forma preferida es el cero morfológico. No obstante, cuando el referente es animado, o sea, no personal, la distribución es equilibrada entre los acusativos y el dativo etimológicos.

En las próximas secciones presentamos la distribución de las estrategias de realización del objeto directo anafórico de $3 \underline{a}$ persona en función de las variables extralingüísticas.

\subsection{Factores extralingüísticos determinantes en la variación}

\subsubsection{El género del informante}

En la tabla 5, presentamos la distribución de las variantes en función del género del hablante.

\begin{tabular}{lll}
\cline { 2 - 3 } & hombre & mujer \\
\hline cero & $65 / 191-34 \%$ & $182 / 625-29,1 \%$ \\
\hline le(s) & $63 / 191-33 \%$ & $127 / 625-20,3 \%$ \\
\hline lo(s)/la(s) & $27 / 191-14,1 \%$ & $187 / 625-29,9 \%$ \\
\hline SN & $25 / 191-13,1 \%$ & $102 / 625-16,3 \%$ \\
\hline dem. & $11 / 191-5,8 \%$ & $27 / 625-4,3 \%$ \\
\hline Tabla 5: Género del informante. & &
\end{tabular}


Lo que se observa en la tabla 5 es que, entre los hombres, las estrategias más frecuentes son cero (34\%) y le(s) (33\%), como ilustran los ejemplos (20) y (21) respectivamente.

(20) l9: Sí me gustaría seguir estudiando sí porque así tenés tu futuro también ((ruido)) yo dejé muy temprano [el estudio] y se me complicaba porque mi familia es pobre digamos y no tenía como para yo seguir estudiando entonces tuve que abandonar $\emptyset_{\mathrm{i}}$ (Hombre, generación 2, nivel inicial)

(21) E: A ¿Sí? Muy bien muy bien Y ¿te acordás de [este chico]?

l9: Sí

E: ¿Qué me contás?

19: No sé no le conocí muy bien pero ((ruido)) por lo que dicen todos tuvo re mal está bien que ahora esté ahí pagando su: (hombre, generación 2, nivel inicial)

Por su parte, las mujeres emplean con mayor frecuencia las formas $l o(s) /$ la(s) (29,9\%) y cero (29,1\%), como se puede observar en los ejemplos (22) y (23), respectivamente. La estrategia le(s) es la tercera variante en lo que se refiere a la productividad, como se observa en el ejemplo (24).

(22) E: Vos/vamos a decir pero algún día escuchaste a [Cristina $]_{i}$ hablando por ejemplo en cadena?

14: No yo $l a_{\mathrm{i}}$ voté a Cristina, la primera vez cuando ella salió presidente yo $l a_{\mathrm{i}}$ voté a Cristina (Mujer, generación 2, nivel secundario)

(23) l11: "a mí no me queda otra voy a consumir droga porque no tengo salida no tengo futuro no tengo nada" y está el chico que lo tiene todo que no tiene más que hacer como es lo que propuso [El Hombre Light $]_{i}$ no sé si lo habrás leído alguna vez te $\emptyset_{\mathrm{i}}$ recomiendo (Mujer, generación 2, nivel terciario)

(24) lo una vez [un lorito] que me regaló mi papá y estaba en la orilla de la silla y un perro ladró al lado de él y como yo le corté la alita por malvada también/no es muy querer también porque si uno $l e_{\mathrm{i}}$ quiere no le va a cortar la alita ¿no? Le corté la alita y $l e_{\mathrm{i}}$ puse en la orilla me fui a jugar con mi amiga y le dejé con mi mamá el lorito (Mujer, generación 1, nivel secundario)

Subrayamos que la estrategia $l o(s) / l a(s)$ no solo es la más empleada entre las mujeres (considerando el universo de todas las formas utilizadas por las mujeres), sino también de las mujeres con relación a los hombres. Entre este último grupo, el porcentaje es de 14,1\%, mientras que entre las mujeres es el doble $(29,9 \%)$.

\subsubsection{La escolaridad del informante}

Una vez que notamos que el nivel de escolaridad puede ser un factor que influye en la selección de las estrategias para la realización del OD anafórico de 3 a persona, presentamos a continuación los resultados del cruce entre las variantes y el factor extralingüístico nivel de escolaridad del hablante. 


\begin{tabular}{llll}
\cline { 2 - 4 } & Nivel 1 & Nivel 2 & Nivel 3 \\
\hline cero & $69 / 175-39,4 \%$ & $72 / 232-31 \%$ & $106 / 409-25,9 \%$ \\
\hline le(s) & $67 / 175-38,3 \%$ & $84 / 232-36,2 \%$ & $39 / 409-9,5 \%$ \\
\hline lo(s)/la(s) & $1 / 175-0,6 \%$ & $36 / 232-15,5 \%$ & $177 / 409-43,3 \%$ \\
\hline SN & $27 / 175-15,4 \%$ & $30 / 232-12,9 \%$ & $70 / 409-17,1 \%$ \\
\hline dem. & $11 / 175-6,3 \%$ & $10 / 232-4,3 \%$ & $17 / 409-4,2 \%$ \\
\hline
\end{tabular}

Tabla 6: Escolaridad del informante. ${ }^{7}$

En la tabla 6, vemos que, entre los hablantes que tienen el nivel inicial, la estrategia más productiva para la realización del OD anafórico de $3^{\mathfrak{a}}$ persona es el cero morfológico (69/175 - 38,3 \%). Cuando el nivel de escolaridad es el secundario, la estrategia más empleada es el pronombre clítico le(s) (84/232 - 36,2 \%). En cambio, cuando el hablante posee el nivel terciario la forma más frecuente son los pronombres clíticos lo(s)/la(s) (177/409-43,3 $\%)$. Llama la atención la elevada frecuencia de uso del cero morfológico en los tres niveles.

Los resultados de la última tabla podrían servir como evidencias empíricas de que las formas vernáculas ${ }^{8}$ en Oberá son el le(s) y cero. Los pronombres $l o(s) / l a(s)$, en nuestra opinión, se relacionan con el nivel de escolaridad. Según aumenta el nivel de escolaridad del hablante, mayor es la frecuencia de uso de los clíticos acusativos. En cambio, el pronombre le(s), por ser la forma de menor prestigio social, presenta una frecuencia de uso considerablemente baja entre los más escolarizados. El cero morfológico, por ser una forma no marcada, al contrario, presenta una elevada frecuencia de uso en los tres niveles de escolaridad. Con todo, aún no queda claro cómo se distribuyen las estrategias entre hombres y mujeres en función del nivel de escolaridad. Por esa razón, presentamos a continuación los resultados del cruce entre el género del informante y la escolaridad.

\subsubsection{Escolaridad por género del informante}

En la tabla 7 presentamos el cruce entre la escolaridad y el género del informante. Lo que buscamos conocer es la distribución de las estrategias analizadas en función de esos dos factores externos.

7 En la tabla 1 explicamos en qué consisten los niveles de escolaridad.

8 En nuestro estudio, empleamos el término vernáculo tal como lo define Carreter (1968). O sea, que se aplica a las lenguas y fenómenos lingüísticos en general para señalar como arraigado en un lugar concreto y que es propio de él. 


\begin{tabular}{|c|c|c|c|c|c|c|}
\hline & \multicolumn{3}{|c|}{ Masculino } & \multicolumn{3}{|c|}{ Femenino } \\
\hline & Nivel 1 & Nivel 2 & Nivel 3 & Nivel 1 & Nivel 2 & Nivel 3 \\
\hline le & $\begin{array}{l}37 / 85 \\
43,5 \%\end{array}$ & $\begin{array}{l}18 / 74 \\
24,3 \%\end{array}$ & $\begin{array}{c}8 / 32 \\
25 \%\end{array}$ & $\begin{array}{l}30 / 90 \\
33,3 \%\end{array}$ & $\begin{array}{l}66 / 158 \\
41,8 \%\end{array}$ & $\begin{array}{l}30 / 377 \\
8 \%\end{array}$ \\
\hline $\mathrm{lo}(\mathrm{s}) / \mathrm{la}(\mathrm{s})$ & $\begin{array}{l}1 / 85 \\
1,2 \%\end{array}$ & $\begin{array}{l}22 / 74 \\
29,7 \%\end{array}$ & $\begin{array}{l}4 / 32 \\
12,5 \%\end{array}$ & $\begin{array}{l}\text { o/90 } \\
\text { ०\% }\end{array}$ & $\begin{array}{l}14 / 158 \\
8,9 \%\end{array}$ & $\begin{array}{l}173 / 377 \\
45,9 \%\end{array}$ \\
\hline cero & $\begin{array}{l}32 / 85 \\
37,6 \%\end{array}$ & $\begin{array}{l}24 / 74 \\
32,4 \%\end{array}$ & $\begin{array}{l}9 / 32 \\
28,1 \%\end{array}$ & $\begin{array}{l}37 / 90 \\
41 \%\end{array}$ & $\begin{array}{l}48 / 158 \\
30,4 \%\end{array}$ & $\begin{array}{l}97 / 377 \\
25,7 \%\end{array}$ \\
\hline SN & $\begin{array}{l}11 / 85 \\
12,9 \%\end{array}$ & $\begin{array}{l}6 / 74 \\
8,1 \%\end{array}$ & $\begin{array}{l}8 / 32 \\
25 \%\end{array}$ & $\begin{array}{l}16 / 90 \\
17,8 \%\end{array}$ & $\begin{array}{l}24 / 158 \\
15,2 \%\end{array}$ & $\begin{array}{l}63 / 377 \\
16,7 \%\end{array}$ \\
\hline dem. & $\begin{array}{l}4 / 85 \\
4,7 \%\end{array}$ & $\begin{array}{l}4 / 74 \\
5,4 \%\end{array}$ & $\begin{array}{l}3 / 32 \\
9,4 \%\end{array}$ & $\begin{array}{l}7 / 90 \\
7,8 \%\end{array}$ & $\begin{array}{l}6 / 158 \\
3,8 \%\end{array}$ & $\begin{array}{l}14 / 377 \\
3,7 \%\end{array}$ \\
\hline
\end{tabular}

Tabla 7: Escolaridad vs. género del informante

Se observa que en el nivel 1 de escolaridad el clítico le(s) es la estrategia más frecuente entre los hombres (37/85 - 43,5\%), en cambio, entre las mujeres con el mismo nivel de escolaridad es el cero morfológico (37/90 - 41\%). En el nivel 2, entre los hombres observamos una distribución equilibrada entre cero (24/74 - 32,4 \%) y lo(s)/la(s) (22/74 - 29,7 \%), mientras que entre las mujeres del mismo nivel $l e(s)$ es la estrategia más frecuente $(66 / 158-41,8 \%)$.

En el nivel 3 de escolaridad, notamos nuevamente una distribución equilibrada entre cero (9/32 - 28,1 \%) y le(s) (8/32 - 25\%) en el habla de los hombres, en cambio, entre las mujeres la estrategia más frecuente es $l o(s) /$ la(s) (173/377 - 45,9 \%). Hay que señalar que el cero morfológico, a pesar de no ser la estrategia más frecuente en todos los niveles de escolaridad, presenta una frecuencia de uso considerablemente alta entre hombres y mujeres en los tres niveles de escolaridad.

Una posible explicación para este resultado es que el factor género del hablante relacionado al nivel de escolaridad determinen la distribución de las formas en variación. En Oberá, es muy frecuente que las mujeres cursen el nivel terciario, mientras que los hombres, después que concluyen el nivel secundario, se dediquen a trabajar en las grandes cadenas de supermercados de la región o en tareas que tienen que ver con la agricultura o con la cosecha y procesamiento de la yerba mate. Así, quienes tienen mayor acceso a la lengua escrita son las mujeres y, por lo tanto, son las mujeres quienes usan las formas consideradas de mayor prestigio social. Esas formas, en Oberá, son los pronombres clíticos $l o(s) / l a(s)$, en oposición a le(s) considerado por los hablantes como una forma "incorrecta".

Para finalizar nuestro análisis en este artículo, buscamos demostrar cuál es la distribución de las variantes en función de la edad del informante. Ese análisis es fundamental, pues nos permite observar si el marco de estrategias observadas indica un panorama de cambio en progreso o de variación estable. 


\section{El factor edad del informante}

Además de los factores género y escolaridad del informante, también es importante analizar la edad. Según la sociolingüística variacionista de Labov, la edad puede indicar el cambio lingüístico en una comunidad de habla, pues se entiende que si hay diferencias entre los miembros de diferentes edades o grupos generacionales habría que interpretarlas como posible resultado de un cambio lingüístico.

El cuadro de variación observado mediante el análisis de los factores sociales puede ser de variación estable o de cambio en curso. En el primer caso, la variación tiende a mantenerse por un largo periodo de tiempo, pues no se verifica una tendencia de predominancia de una variante lingüística sobre otra. En el segundo, el panorama de cambio en curso implica que el proceso de variación se dirige hacia su resolución a favor de una de las variantes identificadas, que primero se generaliza y, después, se hace categórico dentro de la comunidad de habla, haciendo que las demás variantes caigan en desuso. Veamos, entonces, qué ocurre en Oberá:

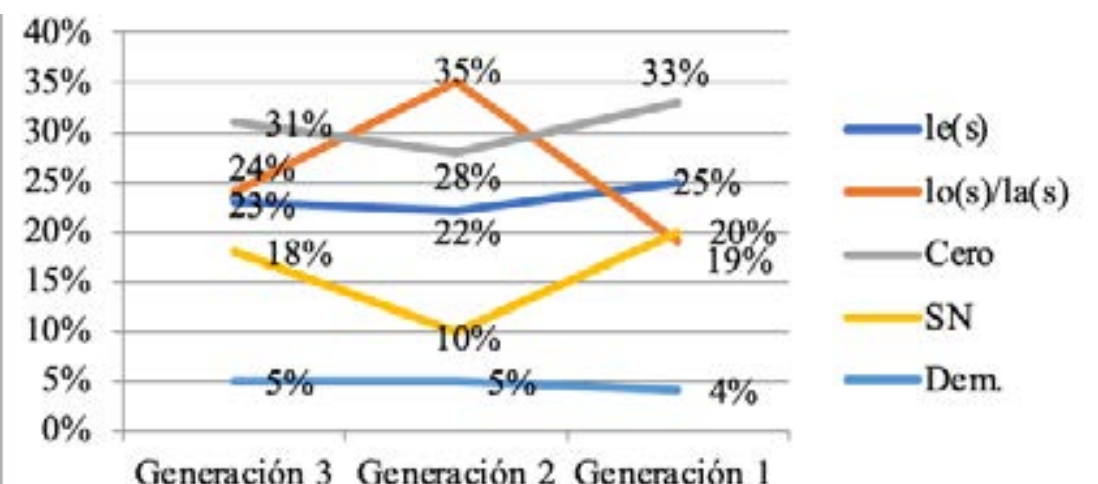

Gráfico 1: Edad del informante.

Notamos que, de manera general, las estrategias más productivas son cero, $l e(s)$ y $l o(s) / l a(s)$. Lo que llama la atención es el alto porcentaje de uso (35\%) de los pronombres clíticos $l o(s) / l a(s)$ en la generación 2, en la que encuentra el pico más elevado. La frecuencia de uso de esos pronombres es menor en las generaciones 3 y 1, en las que se observan (24\%) y (20\%), respectivamente. El pronombre clítico le(s) se comporta de modo análogo al cero morfológico, sin embargo, posee un índice de productividad inferior. El pico más elevado se encuentra en la generación 1, en la que alcanza el $25 \%$ de las apariciones. Eso no implica decir que en las demás generaciones presente una baja frecuencia de uso. Como demuestra el gráfico 1, en la generación 3 , le(s) tiene $23 \%$ de frecuencia de uso y en la segunda generación $22 \%$.

Por lo tanto, mediante la observación de los resultados ilustrados en el gráfico 1 podemos afirmar que el cuadro de estrategias de realización del OD anafórico de 3 a persona demuestra un panorama de variación estable y no de cambio en curso. Podemos ver que el proceso de variación no se dirige 
hacia la resolución a favor de una de las variantes identificadas. Notamos que las formas $l o(s) / l a(s)$ se ven impulsadas, sobre todo, por la generación 2 , más ligada a las formas lingüísticas de prestigio social. Por otro lado, las estrategias le(s) y cero, que son las más productivas en nuestro corpus, no caen en desuso. Estas estrategias se utilizan en las tres generaciones, lo que demuestra que no son sensibles al factor edad. El factor que determina la distribución de le(s) y cero es la animacidad del referente. Finalmente, las estrategias $l o(s) / l a(s)$ no compiten con las demás, ya que el factor que influye en la frecuencia de uso es la escolaridad del hablante. Como en Oberá son las mujeres quienes siguen los estudios terciarios, representan el grupo más escolarizado de la sociedad y, consecuentemente, son quienes emplean con mayor frecuencia estas formas, consideradas de prestigio social.

\section{Conclusiones}

En este artículo, propusimos analizar los resultados de una investigación sociolingüística que analiza la distribución de las variantes empleadas para la realización del objeto directo anafórico de tercera persona del español en términos de frecuencia de uso. Los resultados del análisis variacionista revelan que el cuadro de estrategias de realización del OD anafórico de tercera persona en Oberá-Misiones se compone de cinco variantes: lo(s)/ la(s), le(s), cero morfológico, sintagma nominal y demostrativo. Las dos últimas estrategias son las menos frecuentes en nuestra muestra de habla. Confirmamos la hipótesis que dice que además de le(s) y cero, también son empleados los clíticos $l o(s) / l a(s)$ para la realización del OD en cuestión. Diferentemente a lo señalado en la literatura lingüística sobre el OD en el noreste de Argentina y Paraguay, los pronombres clíticos $l o(s) / l a(s)$ fueron bastante productivos en la muestra de habla de Oberá, con frecuencias próximas a cero y a le(s). Sin embargo, defendemos que las formas etimológicas $l o(s) / l a(s)$ no son las más frecuentes en la comunidad de habla, ya que ese lugar lo ocuparían le(s) y cero. Argumentamos entonces que los pronombres $l o(s) / l a(s)$ son formas consideradas de prestigio en Oberá en oposición a le(s) que sufre estigmatización social, sobre todo por el grupo más privilegiado.

Además, notamos que la distribución de las estrategias le(s) y cero está condicionada principalmente por el factor interno animacidad del referente. Así, el pronombre le(s) se emplea preferencialmente para el OD humano, o personal y retoma antecedentes tanto femeninos como masculinos. Por su parte, el cero morfológico retoma objetos directos inanimados, sean femeninos o masculinos. Este resultado abre un panorama de investigación, una vez que se opone a lo descrito por especialistas en el estudio del OD. En nuestra muestra de habla, le(s) no se relaciona en absoluto con los objetos directos masculinos (según se espera en el sistema referencial, o en el de "compromiso") y lo(s) no se asocia con el OD inanimado (como se esperaría en el sistema referencial) y tampoco con el OD masculino (según se espera en el sistema casual) (García González 1978, 1979; Klein-Andreu 1981, 1992; Fernández-Ordóñez 1993). 
Finalmente, consideramos que el cuadro de estrategias de realización del OD anafórico de $3^{3}$ persona en Oberá indica un panorama de variación estable. Los resultados nos permiten afirmar que le(s) y cero, este último con un elevado índice de frecuencia de uso en nuestra muestra, se encuentran determinados por factores intralingüísticos, como lo es la animacidad del referente. Por ello, opinamos que esa distribución no es sensible al factor edad del informante. Las formas $l o(s) / l a(s)$, por otro lado, no compiten necesariamente con las demás estrategias. Aunque presenten una elevada frecuencia de uso, los antiguos acusativos se emplean principalmente por el grupo con mayor índice de escolaridad, es decir, el grupo que tiene mayor contacto con la lengua escrita y, por lo tanto, con las formas de mayor prestigio social. 


\section{Q Bibliografía}

» Amable, Hugo. 1975. Las figuras del habla misionera. Santa Fe: Colmegna.

» de Granda, Germán. 1982. “Origen y formación del leísmo en el español del Paraguay. Ensayo de un método”. Revista de Filología Española 62: 3-4, 259-284.

» Fernández-Ordóñez, Inés. 1993. “Leîsmo, laîsmo y loîsmo: estado de la cuestión”. En Los pronombres átonos, editado por O. Fernández Soriano, 63-96. Madrid: Taurus Universitaria.

» Fernández Ramírez, Salvador. 1951. Gramática española. Los sonidos. El nombre y el pronombre. Madrid: Manuales de la revista de Occidente.

» García, Erica C. 1992. “Sincronización y desfase del lếsmo y laísmo”. Neuphilologische Mitteilungen, XCIII:2, 235-256.

» García González, Francisco. 1978. “El leísmo en Santander”. Estudios ofrecidos a E. Alarcos Llorach, Ill: 87-101. Universidad de Oviedo.

» García González, Franscisco. 1979. “Los pronombres personales en el oriente de Asturias”. Estudios y trabayos del Seminariu de llingua asturiana, II, 47-56. Universidá d'Uvieu.

» Gómez Seibane, Sara. 2012. Los pronombres átonos (le,la,lo) en el español. Madrid: Arco Libros.

» Klein-Andreu, Flora. 1981. "Distintos sistemas de empleo de le, la, lo. Perspectiva sincrónica, diacrónica y sociolingüística”. Thesaurus, 36: 284-300. Fecha de consulta, otoño de 2016.

» Klein-Andreu, Flora. 1992. "Understanding Standards”. En Explanation in Historical Linguistics, editado por G. Davis y G. K. Iverson, 169-178. Amsterdan: Benjamins.

» Labov, William. 1972. Sociolinguistics patterns. Philadelphia: University of Pennsylvania.

" Labov, William. 1994. Principles of linguistic change. Volume I: Internal factors (Language in Society 20). Oxford: Blackwell.

» Laca, Brenda. 2006. “El objeto directo. La marcación preposicional”. En Sintaxis histórica de la lengua española. Primera parte: La frase verbal, vol.1., editado por C. Company Company, 323-475. México: Universidad Nacional Autónoma de México y Fondo de Cultura Económica.

» Lázaro Carreter, Fernando. 1968. Diccionario de términos filológicos. Madrid: Gredos.

» Martínez, Angelita. 200o. Lenguaje y Cultura. Estrategias etnopragmáticas en el uso de los pronombres clíticos lo, la y le en la Argentina en zonas de contacto con lenguas aborígenes. Leiden: Universidad de Leiden.

» Martínez, Angelita. 2006. "El español de la Argentina en contacto con lenguas indígenas: estrategias etnopragmáticas”. Tópicos del Seminario 15: 97-110. Redalyc, enerojunio de 2006. Fecha de consulta 14 de julio de 2016. http://www.redalyc.org/articulo. oa?id=59401504

» Martínez, Angelita. 2010. “Lenguas y variedades en contacto. Problemas teóricos y metodológicos.” Revista Internacional De Lingüística Iberoamericana 8, no. 1: 9-31. http:// www.jstor.org/stable/41678422.

»Palacios Alcaine, Azucena. 1998. “Variación sintáctica en el sistema pronominal del es- 
pañol paraguayo". Anuario de Lingüística Hispánica, XIV: 451-474.

»Palacios Alcaine, Azucena. 200o. "El sistema pronominal del español paraguayo: un caso de contacto de lenguas”. En Teoría y práctica del contacto: el español de América en el candelero, editado por Pérez Calvo, 122-143. Frankfurt-Madrid: Vervuert-Iberoamericana.

»Palacios Alcaine, Azucena. 2005. “Lenguas en contacto en Paraguay: español y guaraní”. En Variedades lingüísticas y lenguas en contacto en el mundo de habla hispana, editado por C. Ferrero Pino y N. Lasso-von Lan, 35-43. Bloomington: Books Library.

»Quilis, Antonio, Margarita Cantarero, María José Albalá, y Rafael Guerra. 1985. Los pronombres "le”, “la”, "lo” y sus plurales de la lengua española hablada en Madrid. Madrid: Instituto de Filología Hispánica.

»Sankoff, David, Sali Tagliamonte y Eric Smith. 2005. En línea. GoldvarbX. Computer program. Department of Linguistics, University of Toronto. http://individual.utoronto.ca/ tagliamonte/goldvarb.html

» de Ramos, Patricia Vanessa. 2017. "Estratégias de realização do objeto direto anafórico de $3^{\text {a }}$ pessoa no espanhol de Oberá - Misiones (Argentina): um estudo sociolinguístico”. Tesis de master, Universidade Federal do Rio de Janeiro.

»Real Academia Española y Asociación de Academias de la Lengua Española. 2009. Nueva gramática de la lengua española. Morfología y sintaxis. Madrid: Espasa.

»Weinreich, Uriel, William Labov y Marvin I. Herzog. 2006. Fundamentos empíricos para uma teoria da mudança linguística. Tradução de Marcos Bagno. São Paulo: Parábola. 